DISTRIBUTION STATEMENT A. Approved for public release; distribution is unlimited.

\title{
Interactions Among Behavioral Responses of Baleen Whales to Acoustic Stimuli, Oceanographic Features, and Prey Availability
}

Ari S. Friedlaender, PhD \& Brandon L. Southall, PhD

Southall Environmental Associates, Inc.

9099 Soquel Drive, Suite 8

Aptos, CA 95003

phone: (831) 661-5177 fax: (831) 661-5178 email: ari.friedlaender@oregonstate.edu

phone: (831) 661-5177 fax: (831)661-5178 email: Brandon.Southall@sea-inc.net

Elliott L Hazen, PhD

UC Santa Cruz - Institute of Marine Sciences

NOAA SWFSC Environmental Research Division

1352 Lighthouse Ave.

Pacific Grove, CA 93950

phone: (831) 658-3202 fax: (831) 648-8440 email: Elliott.hazen@noaa.gov

Award Numbers:

N000141210284 / N000141310789 (Friedlaender)

N000141310790 / N0001413IP20034 / N0001412IP20071 (Hazen)

www.socal-brs.org

\section{LONG-TERM GOALS}

The long term goals of this collaborative research effort, which is coordinated with other ONR and Navy-funded biological research projects, are two-fold. Our first objective is to determine how the distribution, abundance, and behavior of prey affects the baseline foraging behavior and ecology of baleen whales off the California coast. The basic measurements of foraging ecology and behavior are also providing a critical means of interpreting potential responses buy describing the energetic consequences of any observed changes in behavior. Baleen whales employ a variety of feeding strategies that relate to the behavior of their prey and understanding these is paramount to being able to assess changes in their feeding ecology arising from a host of natural and human factors. Second, we are using these findings directly in quantifying how prey affects whale behavior and ultimately interpretation of response to anthropogenic sound. Given the broader goals of investigating potential behavioral responses of whales to mid-frequency military sonar, the ability to more completely describe and quantify behavioral responses of baleen whales to controlled exposure experiments while including the effects of prey provides a novel and powerful insight into interpreting responses to sound and controlling for environmental factors. In order to determine whether and how behavioral changes occurring in baleen whales during controlled exposure experiments are related to sound in their environment, we are applying these integrated methods to better understand and quantify whether and how changes in their prey environment account for the behavioral change as well. In baleen whales, the behavioral states most commonly observed are feeding, traveling, resting, and socializing. Blue whales visit the southern California Bight in the summer months primarily to forage, and therefore 


\section{Report Documentation Page}

Form Approved

OMB No. 0704-0188

Public reporting burden for the collection of information is estimated to average 1 hour per response, including the time for reviewing instructions, searching existing data sources, gathering and maintaining the data needed, and completing and reviewing the collection of information. Send comments regarding this burden estimate or any other aspect of this collection of information,

including suggestions for reducing this burden, to Washington Headquarters Services, Directorate for Information Operations and Reports, 1215 Jefferson Davis Highway, Suite 1204, Arlington

VA 22202-4302. Respondents should be aware that notwithstanding any other provision of law, no person shall be subject to a penalty for failing to comply with a collection of information if it

does not display a currently valid OMB control number.

1. REPORT DATE

30 SEP 2014

4. TITLE AND SUBTITLE

Interactions Among Behavioral Responses of Baleen Whales to Acoustic

Stimuli, Oceanographic Features, and Prey Availability

6. AUTHOR(S)

7. PERFORMING ORGANIZATION NAME(S) AND ADDRESS(ES)

Southall Environmental Associates, Inc.,9099 Soquel Drive, Suite

8,Aptos,CA,95003

9. SPONSORING/MONITORING AGENCY NAME(S) AND ADDRESS(ES)

12. DISTRIBUTION/AVAILABILITY STATEMENT

Approved for public release; distribution unlimited

13. SUPPLEMENTARY NOTES

14. ABSTRACT

15. SUBJECT TERMS

16. SECURITY CLASSIFICATION OF:

a. REPORT

unclassified

b. ABSTRACT

unclassified c. THIS PAGE

unclassified
17. LIMITATION OF ABSTRACT

Same as

Report (SAR)
3. DATES COVERED

00-00-2014 to 00-00-2014

5a. CONTRACT NUMBER

5b. GRANT NUMBER

5c. PROGRAM ELEMENT NUMBER

5d. PROJECT NUMBER

5e. TASK NUMBER

5f. WORK UNIT NUMBER

8. PERFORMING ORGANIZATION REPORT NUMBER

10. SPONSOR/MONITOR'S ACRONYM(S)

11. SPONSOR/MONITOR'S REPORT NUMBER(S) 
understanding baseline behavior (such as how changes in their prey affect the likelihood of changing behavioral states) is necessary to adequately describe, understand, and effectively mitigate the affects of anthropogenic sound, including military sonar, on these animals.

\section{OBJECTIVES}

The overall objectives of this multi-year study are to obtain empirical synoptic measurements of finescale prey distribution and whale diving and foraging behavior in order to better understand baleen whale foraging ecology and better interpret responses to experimental sound exposure. The current project has already enabled us to obtain basic distribution and density information for prey concurrent with foraging mysticete cetaceans during tagging with fine-scale movement sensors in the context of behavioral response studies (specifically the Southern California Behavioral Response Study, or SOCAL-BRS). The new results in FY14 here clearly and quite powerfully demonstrate that data on the distribution and abundance of prey are essential in fully understanding how changes in whale behavior related to the presence of human sounds are mediated by these factors and associated environmental variables. Subsequent CEEs involving potential behavioral changes in foraging marine mammals should build on these novel techniques and measurements in order to fully describe potential responses (or lack thereof) to sound exposure.

\section{APPROACH}

SIMRAD EK60 echosounder units (38 and $120 \mathrm{kHz}$ echosounders and GPTs) and top-side hardware were made available for the project through collaborations with research partners at Duke University (Dr. Doug Nowacek). A specialized echosounder mount and towfish appropriate for the SOCAL-BRS platform was fabricated with support from this award (Figure 1). The smaller orange echosounder is the $120 \mathrm{kHz}$ unit and the larger echosounder is the $38 \mathrm{kHz}$ unit.

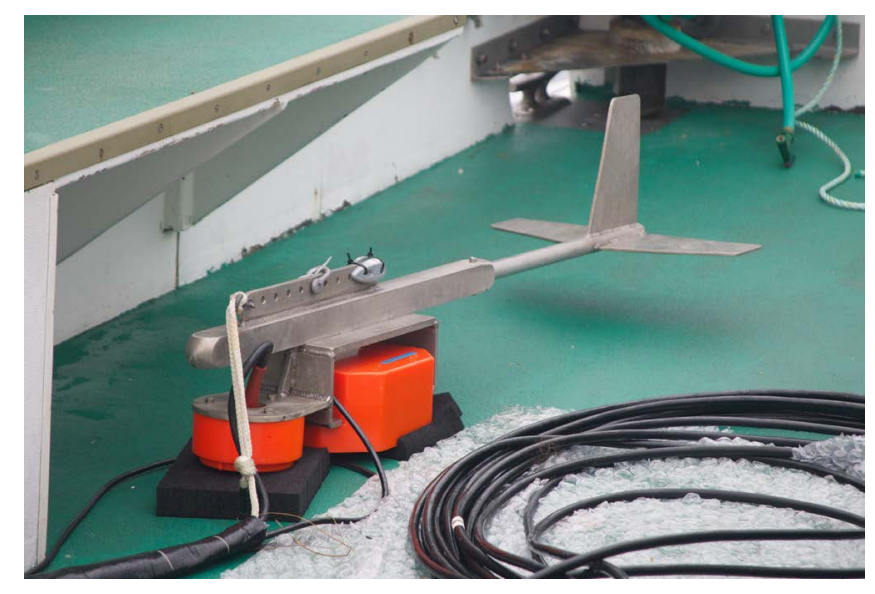

\section{Figure 1. The two echosounder units mounted on the towfish}

Several computers were required, including a ruggedized laptop computer specific to data acquisition (Dell Latitude E6420 ATG) and a laptop computer for field/lab data analysis (MacBook Pro 15.4/2.3/2X2GB/750/SD/HR-AG). Additionally, several external data storage drives and other ancillary gear (e.g., handheld GPS unit) were required and obtained with this award. The information from each echosounder is processed in a GPT (general purpose transceiver) that also acts as a power supply. The data are then streamed through Ethernet cables to the laptop where they are processed in 
customized visualization and analysis software (Echoview). The data are stored directly on the laptop computer and then backed up on multiple external hard drives routinely. A hand-held Garmin GPS unit is connected to the laptop to provide a time and location stamp for the echosounder data as it is acquired.

Finally, a plankton sampling system was obtained for the second leg of the project, given the interesting measurements made initially and the inability to obtain plankton species identifications. This consisted of a triple-stitched plankton net $(100 \mathrm{~cm}$ X $500 \mathrm{~cm}$ X 1000 Microns x $11 \mathrm{~cm}$ diam; 4.5"0 COD end aperature), an SS-ring and bridle assembly, a complete 2-PC PVC COD end assembly (1000 microns), and a mechanical flow-meter (Figure 2). In order to quantify the density and biomass of prey measured from the echosounders, we need to generate length-frequency estimates of the actual targets that are being measured. Thus, incorporating the net into our sampling protocols will allow for more accurate and quantitative estimates of prey for our analysis.

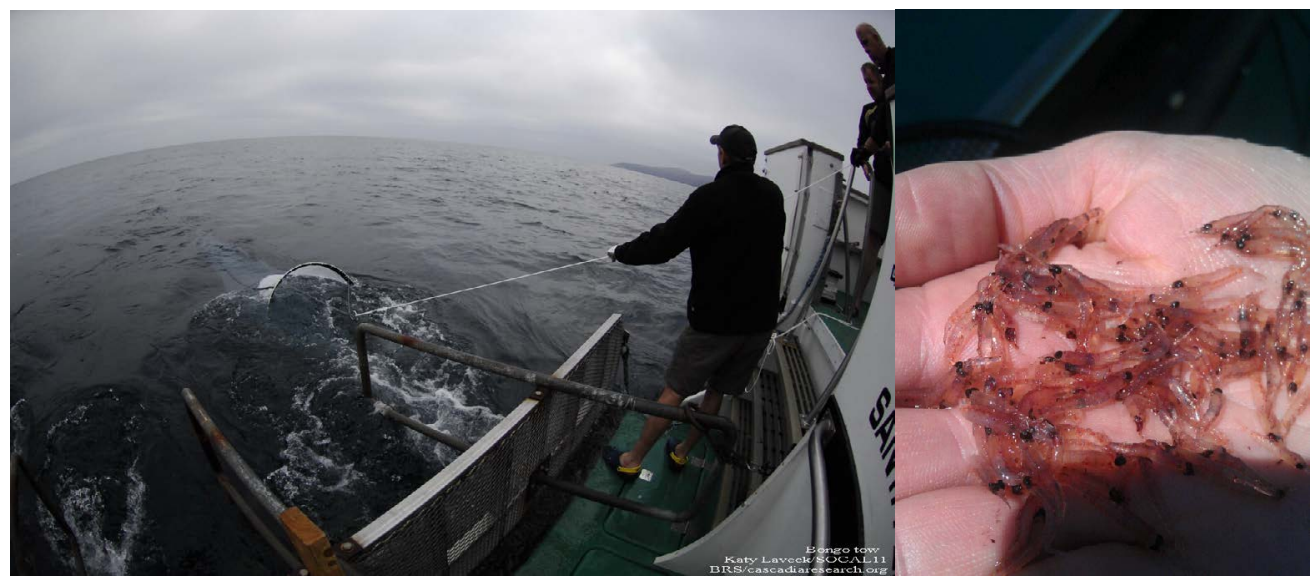

\section{Figure 2. Left: the net assembly being deployed form the back of the SOCAL-BRS research vessel. Right: Sample of krill.}

Fine-scale prey density and distribution and individual predator behavior was measured in two phases in SOCAL-11 (late-July to mid-August and September 2011) and in the first phase of SOCAL-12 (July-Aug 2012) using the existing research platform $(R / V$ Truth). By analyzing prey and predator at fine scales (100s of meters), we can begin to test for the relationships between prey distribution and predator behavior and understand the ecological decisions made by individual whales when foraging, and how the broader oceanographic environment affects blue whales in southern California.

Prey sampling - Prey distribution and abundance was continuously measured using 38 and $120 \mathrm{kHz}$ SIMRAD EK60 echosounders at fine scales $(<10 \mathrm{~km})$. Acoustic data collected in the absence of sighted or tagged whales were treated as a control measure of ambient prey density. Fine scale sampling methods are dependent on the behavior of the tagged whale so an iterative approach to sampling prey is employed. If the tagged whale is traveling ( $>1 \mathrm{~km}$ per hour displacement), a zig-zag design was used to survey prey distributions passed over by the whale by sampling in its wake $(\sim 1.4 \mathrm{~km}$ long transects). When focal whales were surface feeding (defined as observing the animal with its mouth gaped or bubbles located where the animal surfaced), a clover leaf sampling design allowed the measurement of prey abundance and distribution, with the center of the sampling box centered around the whale (Figure 3). The sampling design around non-feeding and non-traveling (i.e. resting) individuals is identical, with a cloverleaf used to examine the prey distribution in the absence 
of feeding. When measuring prey relative to surfacing events, transects were designed to pass within 500 meters of the tagged whale. Correlations between whale behavior, prey data, and environmental data, will only be considered in analysis within a 500m radius of a whale surfacing. This will allow us to quantify the distribution, abundance and dimensions of prey patches in close proximity to foraging and non-foraging whales. We will also compare the two frequencies of acoustic data to differentiate krill from larger fish targets as krill have greater backscatter at $120 \mathrm{kHz}$ than $38 \mathrm{kHz}$.

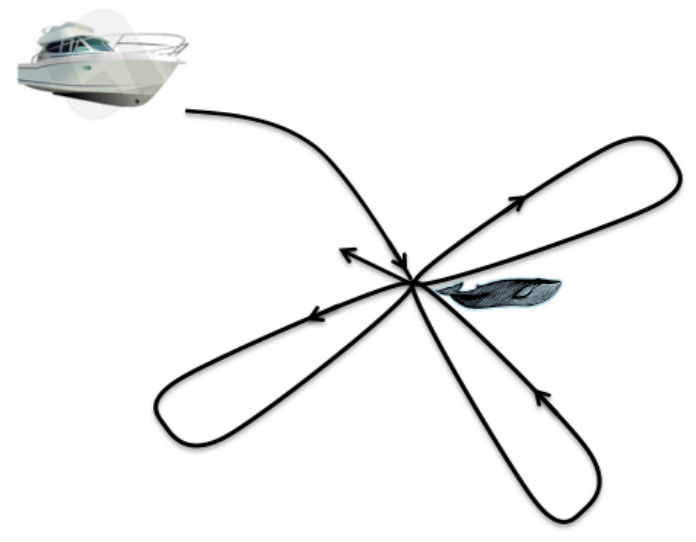

Figure 3. Clover leaf sampling design around tagged whale. Each leaf is $1 \mathrm{~km}$ from the center.

Whale data - Whale behavior (e.g., feeding/non-feeding) is inferred from the tag record in combination with near continuous daytime focal surface observations. Tags were attached from $\sim 6 \mathrm{~m}$ rigid-hulled inflatable boats (RHIB) by taggers using hand-held poles from which Woods Hole Oceanographic Institution (WHOI) Digital Acoustic tags (DTAG) were deployed. The DTAG is a small, lightweight, pressure tolerant tag capable of recording data for up to 20 hours and attached to the whale via suction cups. The DTAG measures the acceleration in the animal's pitch, roll, and heading, as well as depth, and water temperature at $50 \mathrm{~Hz}$. The tags also measure sound and calibrations have been made between vertical acceleration and flow noise to determine when whales lunge underwater. This is determined by increased acceleration as the whale approaches a prey patch and dramatic deceleration when the animal opens it mouth to lunge and engulf prey. This approach has been published and ground-truthed for several species of baleen whales, including blue whales and thus is considered the most accurate way of determining feeding events in baleen whales from tag-derived records. Data from the pitch record also allows for analysis of fluke stroke rates and relative stroke amplitudes and combined with behavioral observation allows the identification of surface feeding bouts and quantification of their duration. All sensor data are stored in flash memory on the tag and are downloaded via an infrared connection to a computer for analysis. The tag has a VHF antenna that transmits when at the surface, allowing us to follow the whale when it is either out of visual range or during nighttime. Focal follows were conducted from RHIBs such that animal's position was recorded by marking a GPS position at the location (foot-print) and time where the tagged whale made a terminal dive. Additionally, we augmented this method by collecting high-resolution range and bearing measurements using a laser range-finder (Leica Vector IV), to georeference the surfacing locations of the tagged whale more frequently. Similar to previous studies using non-linear generalized additive models, in analysis we will quantify the effects of remotely sensed environmental features and prey abundance on the distribution and abundance of whales at the seascape scale. This approach will provide estimates of (1) prey and environment in the functional study area around blue 
whales and (2) the functional relationships between prey density and school size and predator aggregation size.

\section{WORK COMPLETED}

- Prey mapping data were collected concurrent to baleen whale tagging and playback experiments on during each of the SOCAL-12 and SOCAL-13 field efforts while towing the prey mapping towfish ( 8 total weeks of field effort).

- Submission of the manuscript: "Feeding performance by sympatric blue and fin whales exploiting a common prey resource”, by Ari S. Friedlaender, J. Goldbogen, E. Hazen, J. Calambokidis, and B. Southall, to Marine Mammal Science.

- Analysis of prey data and fine scale whale kinematics to be combined in ecological and BRS analyses.

- Initial statistical approach incorporating echosounder prey data in models of blue whale behavioral responses as an environmental covariate.

\section{RESULTS}

We conducted prey mapping both before and after controlled exposure experiments (CEEs) associated with 10 blue and 2 fin whales during SOCAL-11 and SOCAL-12 that were included in the analysis depicted below. Additionally, we have collected prey data either before or after behavioral response experiments on 10 blue whales during SOCAL-13. We have finished the final stages of the SOCAL-14 field effort last month and have collected additional CEE prey measurements from 12 blue whales and 1 fin whale in 2014 (including controls).

\begin{tabular}{|l|l|c|c|c|}
\hline \multicolumn{5}{|c|}{$\begin{array}{c}\text { Table Species tagged and prey-mapping type through 2014. Largest data gaps } \\
\text { include real Navy sonar, fin whales, and blue whale controls. }\end{array}$} \\
\hline Date & Species & Pre-exposure & Post-Exposure & Control \\
\hline $7 / 29 / 11$ & Blue Whale & $\mathbf{X}$ & $\mathbf{X}$ & \\
\hline $7 / 29 / 11$ & Blue Whale & & $\mathbf{X}$ & \\
\hline $7 / 30 / 11$ & Blue Whale & $\mathbf{X}$ & $\mathbf{X}$ & \\
\hline $7 / 31 / 11$ & Blue Whale & & & $\mathbf{X}$ \\
\hline $8 / 1 / 11$ & Blue Whale & $\mathbf{X}$ & $\mathbf{X}$ & \\
\hline $8 / 2 / 11$ & Blue Whale & $\mathbf{X}$ & & \\
\hline $8 / 2 / 11$ & Blue Whale & & $\mathbf{X}$ & \\
\hline $8 / 3 / 11$ & Blue Whale & & & $\mathbf{X}$ \\
\hline $8 / 3 / 11$ & Blue Whale & $\mathbf{X}$ & $\mathbf{X}$ & \\
\hline $8 / 6 / 11$ & Blue Whale & $\mathbf{X}$ & $\mathbf{X}$ & \\
\hline $8 / 6 / 11$ & Blue Whale & $\mathbf{X}$ & & \\
\hline $8 / 7 / 11$ & Blue Whale & & $\mathbf{X}$ & \\
\hline $8 / 8 / 11$ & Blue Whale & $\mathbf{X}$ & $\mathbf{X}$ & \\
\hline $8 / 9 / 11$ & Blue Whale & & $\mathbf{X}$ & \\
\hline $8 / 9 / 11$ & Blue Whale & X & $\mathbf{X}$ & \\
\hline $8 / 4 / 12$ & Blue Whale & & $\mathbf{X}$ & \\
\hline $8 / 4 / 12$ & Blue Whale & & & \\
\hline
\end{tabular}




\begin{tabular}{|l|l|c|c|c|}
\hline $8 / 4 / 12$ & Fin Whale & $\mathbf{X}$ & $\mathbf{X}$ & \\
\hline $10 / 18 / 12$ & Blue Whale & $\mathbf{X}$ & $\mathbf{X}$ & \\
\hline $10 / 20 / 12$ & Fin Whale & $\mathbf{X}$ & $\mathbf{X}$ & \\
\hline $7 / 26 / 13$ & Blue Whale & $\mathbf{X}$ & $\mathbf{X}$ & $\mathbf{X}$ \\
\hline $8 / 2 / 13$ & Blue Whale & $\mathbf{X}$ & $\mathbf{X}$ & $\mathbf{X}$ \\
\hline $8 / 4 / 13$ & Fin Whale & $\mathbf{X}$ & $\mathbf{X}$ & \\
\hline $8 / 5 / 13$ & Blue Whale & $\mathbf{X}$ & $\mathbf{X}$ & \\
\hline $9 / 14 / 13$ & Fin Whale & $\mathbf{X}$ & $\mathbf{X}$ & \\
\hline $9 / 14 / 13$ & Fin Whale & $\mathbf{X}$ & $\mathbf{X}$ & \\
\hline $9 / 15 / 13$ & Fin Whale & $\mathbf{X}$ & $\mathbf{X}$ & \\
\hline $9 / 15 / 13$ & Fin Whale & $\mathbf{X}$ & $\mathbf{X}$ & \\
\hline $9 / 16 / 13$ & Blue Whale & $\mathbf{X}$ & $\mathbf{X}$ & \\
\hline $9 / 16 / 13$ & Fin Whale & $\mathbf{X}$ & $\mathbf{X}$ & \\
\hline $7 / 30 / 14$ & Blue Whale & $\mathbf{X}$ & & \\
\hline $7 / 30 / 14$ & Blue Whale & $\mathbf{X}$ & $\mathbf{X}$ & \\
\hline $7 / 31 / 14$ & Blue Whale & $\mathbf{X}$ & & $\mathbf{X}$ \\
\hline $8 / 01 / 14$ & Blue Whale & $\mathbf{X}$ & $\mathbf{X}$ & $\mathbf{X}$ \\
\hline $8 / 05 / 14$ & Blue Whale & $\mathbf{X}$ & & $\mathbf{X}$ \\
\hline $8 / 06 / 14$ & Blue Whale & $\mathbf{X}$ & $\mathbf{X}$ & \\
\hline $8 / 06 / 14$ & Blue Whale & $\mathbf{X}$ & & \\
\hline $9 / 8 / 14$ & Blue Whale & & & $\mathbf{X}$ \\
\hline $9 / 13 / 14$ & Blue Whale & $\mathbf{X}$ & $\mathbf{X}$ & \\
\hline $9 / 16 / 14$ & Fin Whale & & & $\mathbf{X}$ \\
\hline $9 / 18 / 14$ & Blue Whale & & $\mathbf{X}$ & \\
\hline $9 / 19 / 14$ & Blue Whale & $\mathbf{X}$ & $\mathbf{X}$ & \\
\hline $9 / 19 / 14$ & Blue Whale & $\mathbf{X}$ & & \\
\hline
\end{tabular}

We have explored the fine scale kinematics and energetics of blue whale feeding behavior using the Dtag sensor (e.g. accelerometer) data relative to acoustically measured prey patches. Describing this baseline behavior is critical for understanding how blue whale foraging decisions vary as a function of prey distribution and abundance. We have found that 1) blue whales are targeting krill patches with respect to patch density more than patch depth building upon previous papers that have shown a strong depth selection independent of krill density (Croll et al. 2002; Doniol-Valcroze et al. 2011). As krill densities increase, the number of feeding lunges per dive increases as well even though other prey patches are available to a foraging whale (Figure 4). This implies that understanding prey patch quality is critical in assessing if whales conform to optimal foraging theory in the marine environment. In addition, whale feeding lunges were more dynamic in their kinematic motion; more likely to have increased pitch and roll during lunges when prey patch density was lower; higher densities of prey led to straight lunges compared to the acrobat $180^{\circ}$ and $360^{\circ}$ rolls (whale and prey from $7 / 29 / 2011$ and $8 / 01 / 2011$; Figure 5). The optimal foraging manuscript is in final draft form with plans for it to be submitted to Nature by November, 2014. 


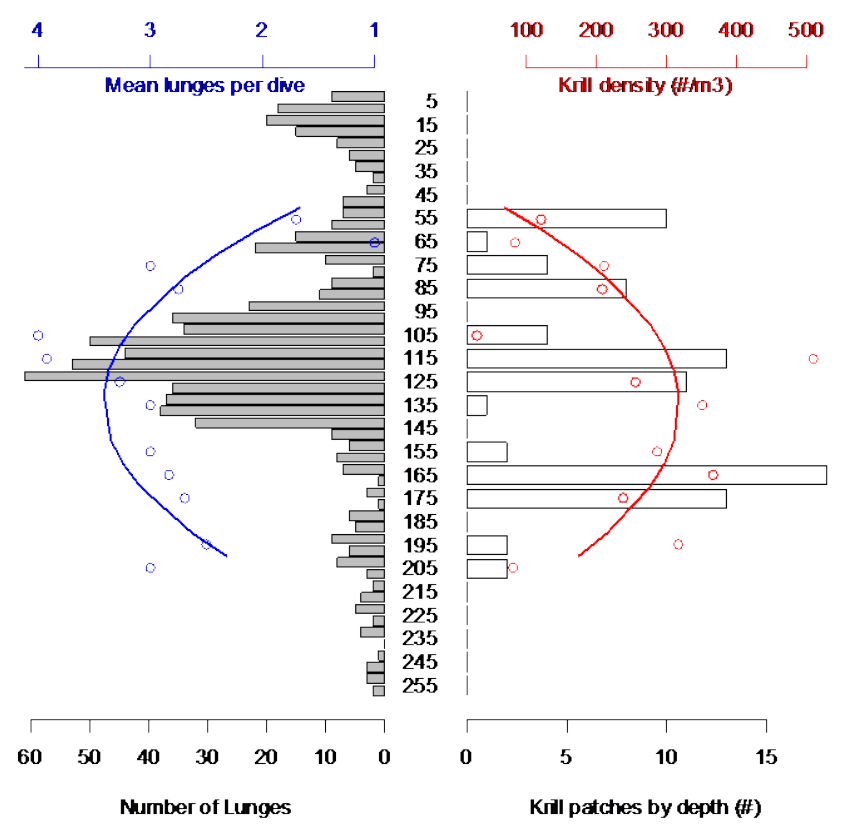

Figure 4. Left: Number of lunges and lunges per dive (blue) and Right: krill patch depth and krill patch density (red).

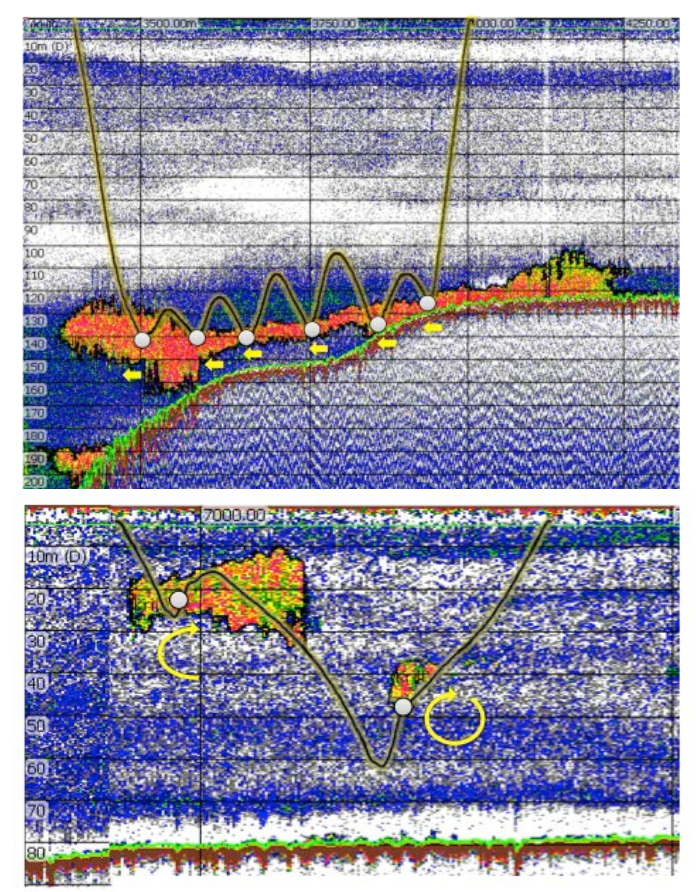

Figure 5. Dense patches of krill were correlated with straight lunges (above) compared to the more acrobatic 180 and $360^{\circ}$ rolls at lower patch densities (below).

We used generalized additive mixed models (GAMM) with individual whale as a random covariate to assess the effect of prey density and patch structure on whale feeding kinematics. Results from pitch and roll models indicate that whales are more acrobatic when foraging on less dense patches (Figure 6 
below). All of this is critical in putting behavioral responses in context to the baseline ecology of these top predators. This paper is in review at Functional Ecology (Goldbogen et al. in review).
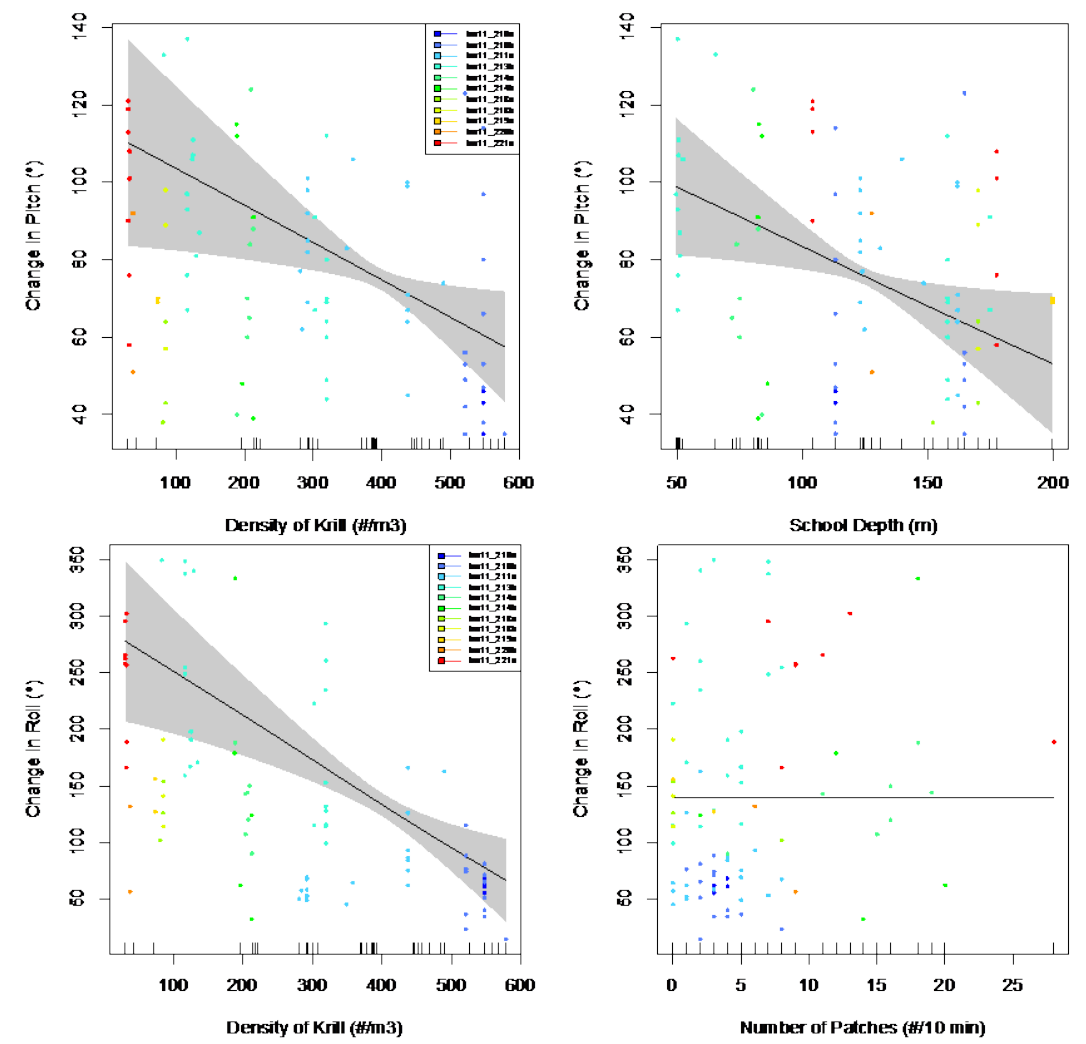

Figure 6. Relationships between changes in pitch (top) and roll (bottom) in blue whale feeding behavior as a function of krill density (\#/m3), krill patch depth, and the number of krill patches measured.

\section{Blue Whale Response mediated by prey}

We have completed analyses on the prey mediated response to sonar playbacks using the PCA-GAMM approaches described in Goldbogen et al. 2013. Given we have prey data only before and after the playbacks, we were not able to include a "during" state so any behavioral state changes that returned to normal upon cessation of playback would not be detected. The GAMM examining response in dive axis 1 (dive time, surface time, breaths, dive depth, etc.) showed a significant before-after effect including potential changes in prey. However, we found that bottom depth, school height, and school depth explained significantly more variability in dive axis 1 than playback alone $\left(\mathrm{r}^{2}=0.703\right.$ for the best-fit model shown in Table 2, Figure 7); treatment type (MFA or PRN) was not significant for any of the models. This makes the argument that a) prey are critical in understanding behavioral changes $\left(\mathrm{r}^{2}\right.$ with prey of 0.703 compared to $\mathrm{r}^{2}$ of 0.14 for PCA-GAMM on Dive Axis 1 in Goldbogen et al. 2013) and b) we prey measurements during exposure would be useful to collect as many whales returned to pre-exposure behavior immediately following acoustic playbacks. Given the high amount of variance explained by the mathematical models that include prey parameters, we will also examine how prey changes may have affected individual whale responses in the Mahalanobis distance / change- 
point analysis approach currently underway by the SoCal BRS team. As these techniques are still being developed, we have prepared the prey framework for inclusion but are waiting for the complete analyses. Together the PCA-GAMM across individual analyses and the individual time series analyses are part of a complete draft manuscript targeted to a journal such as Proceedings B Biology for submission by November 2014.

\begin{tabular}{|c|c|c|c|c|}
\hline \multicolumn{5}{|c|}{$\begin{array}{c}\text { Table 2. GAMM summary for best-fit model with Dive Axis } 1 \text { as } \\
\text { a function of prey and playback state. }\end{array}$} \\
\hline & $\begin{array}{r}\text { Degrees of } \\
\text { freedom }\end{array}$ & F statistic & p-value & \\
\hline Before-After & 1.1803 & 3.271 & 0.0017 & $* *$ \\
\hline $\mathrm{s}\left(\mathrm{Sv} \_\right.$mean $)$ & $4.95 \mathrm{E}-07$ & 0 & 0.388375 & \\
\hline s(Height_mean) & $9.40 \mathrm{E}-01$ & 3.501 & 0.000147 & $* * *$ \\
\hline s(Depth_mean) & $2.47 \mathrm{E}+00$ & 17.595 & $1.68 \mathrm{E}-12$ & $* * *$ \\
\hline s(BotDep) & $9.79 \mathrm{E}-01$ & 9.848 & 8.91E-09 & $* * *$ \\
\hline$r^{2}=0.703$ & & & & \\
\hline
\end{tabular}
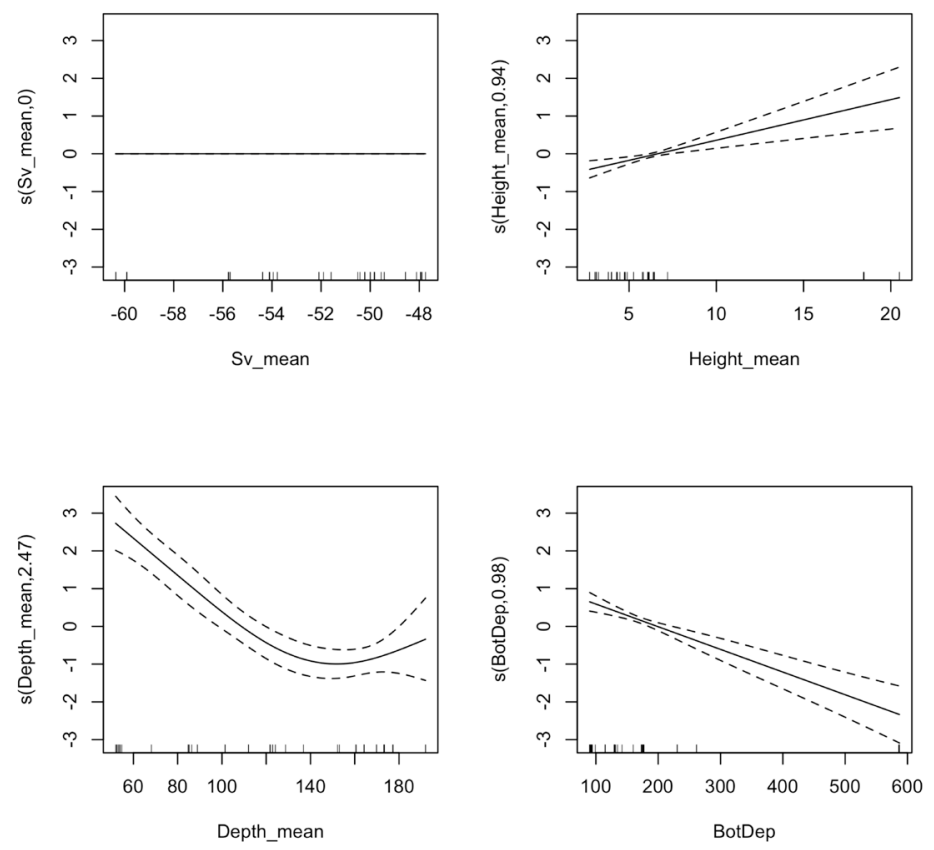

Figure 7. Dive axis 1 generalized additive mixed model output showing how dive behavior changes significantly as prey patches change.

\section{IMPACT / APPLICATIONS}

Our research to date has significantly increased our understanding of baleen whale feeding behavior and foraging ecology (Friedlaender et al. in prep, Goldbogen et al. in prep, Hazen et al. in prep). We have also completed analyses that will contribute significantly to our ability to understand how the fine-scale kinematics of baleen whale feeding are affected by changes in the distribution, abundance, 
and behavior of their prey. This information will provide critical baseline knowledge to interpret behavioral responses of baleen whales to anthropogenic sounds. Understanding how baleen whale foraging conforms to ecological theory (optimal foraging theory) and how changes in prey behavior affect the complexity of feeding behaviors will increase our understanding of baleen whales significantly can be compared to similar field studies across other species and in different locations.

Finally, our latest analyses augment our initial findings of the behavioral responses of blue whales to anthropogenic sounds. Specifically, including quantitative metrics of prey patches being targeted by whales actively feeding during behavioral response experiments significantly increases the predictive power of our statistical models. In our recently published blue whale response paper (Goldbogen et al. 2013), the behavioral response analysis including whale kinematic data but no prey data had an $r^{2}$ of 0.14 . Running the same model (GAMM) including prey patch metrics increased the $r^{2}$ to 0.703 , and the most significant factors in this model were all related to prey. Response to playback was still significant given prey covariates, which corroborates Goldbogen et al. (2013), but specific examination of individual responses is critical to further tease this apart. Thus, we have achieved greater understanding of prey-mediated behavioral responses in baleen whales. This is important information for the behavioral response study because with such increased explanatory power for when changes in whale behavior can be detected, we can more specifically characterize how whale behavior is affected by sound exposure.

Since the inception of the ONR prey-mediated project, our team has led 1 paper (Friedlaender et al. 2014), co-authored 2 papers (Goldbogen et al. 2012, 2013), and have 3 more papers in review or to be submitted shortly (Friedlaender et al. in prep, Hazen et al. in prep, Goldbogen et al. in review).

\section{RELATED PROJECTS}

This project is directly integrated into the Southern California Behavioral Response Study (SOCALBRS - see: www.socal-brs.org). This is a novel research effort which is measuring behavior and responses to both simulated and actual mid-frequency sonar and other signals in marine mammals. The prey-mapping measurements for this project are leveraging boat time and other logistical support from the ongoing SOCAL-BRS project, while providing data that are directly relevant to interpreting the behavioral responses of mysticetes to controlled exposure experiments. Publications resulting from both projects will utlize data and analyses supported under the current award.

\section{REFERENCES}

Croll, D.A., Marinovic, B., Benson S., Chavez, F.P., Black, N., Ternullo, R., and Tershy, B.R. 2005. From wind to whales: trophic links in a coastal upwelling system. Mar. Ecol. Prog. Ser. 289: 117130.

Doniol-Valcroze, T., V. Lesage, J. Giard, and R. Michaud. 2011. Optimal foraging theory predicts diving and feeding strategies of the largest marine predator. Behavioral Ecology 22: 880-888.

Friedlaender A.S., G.L. Lawson, P.N. Halpin. 2009. Evidence of resource partitioning between humpback and minke whales around the western Antarctic Peninsula. Marine Mammal Science. 25: 402-415. 
Friedlaender, A. S., J. A. Goldbogen, E. L. Hazen, J. Calambokidis, and B. L. Southall. 2014. Feeding performance by sympatric blue and fin whales exploiting a common prey resource. Marine mammal science.

Foote, K.G., H.P. Knudsen, G. Vestnes, D.N. MacLennan, and E.J. Simmonds. 1987. Calibration of acoustic instruments for fish density estimation: a practical guide. International Council for the Exploration of the Sea (ICES) Cooperative Research Report No. 144. Published by NRC Research Press

Goldbogen, J. A., J. Calambokidis, A. S. Friedlaender, et al. (2012). Underwater acrobatics by the world's largest predator: 360_ rolling maneuvers by lunge-feeding blue whales. Biology Letters. doi:10.1098/rsbl.2012.0986.

Goldbogen J.A., Southall B.L., DeRuiter S.L., Calambokidis J., Friedlaender A.S., Hazen E.L., Falcone E.A., Schorr G.S., Douglass A., Moretti D.J., Kyburg C., McKenna M.F., Tyack P.L. (2013). Blue whales respond to simulated mid-frequency military sonar. Proc R Soc B 20130657. http://dx.doi.org/10.1098/rspb.2013.0657

E.L. Hazen, A.S. Friedlaender, M. Thompson, C. Ware, M. Weinrich, P. Halpin, D. Wiley. 2009. Three dimensional prey aggregations and fine scale foraging ecology of Humpback whales (Megaptera novaengliae). Marine Ecology Progress Series 395: 75-89.

Watkins, J.L., and A.S. Brierley. 2002. Verification of acoustic techniques used to identify and size Antarctic krill. ICES J. Mar. Sci. 59(6):1326-1336. doi:10.1006/jmsc.2002.1309. 